\title{
BREVE TRAJETO DA FORMAÇÃO BRASILEIRA EM ARTES CÊNICAS NO ENŞINO SUPERIOR
}

\section{Brief path of Brazilian performing arts degree education}

\author{
Henrique Bezerra de Souza \\ Universidade do Estado de Santa Catarina - UDESC
}

Resumo: O artigo visa apresentar um breve histórico sobre a formação em teatro no Brasil, enfocando a sua inserção no ensino superior. Para tanto, utiliza em sua investigação registros históricos, leis e estudos da área. A partir deste material traça uma breve discussão sobre as heranças deste percurso até a universidade e seus possíveis ecos no ensino.

Palavras-chave: Ensino do teatro; História; Formação do ator/atriz.

Abstract: This article aims to presents a brief history of theater education in Brazil, focusing its insertion on degree teaching. In order to do this, investigates historic records, laws and theater studies. From this material, draws a brief discussion about possible legacies of this path until university and its echoes in teaching.

Keywords: Theater teaching; History; Actor/actress training. 
"Por que vocês estão aqui? Para ser artista não é necessário fazer uma faculdade". Era com esta provocação que abria as aulas que ministrava nas disciplinas de atuação e prática teatral dos cursos superiores nos quais trabalhei. Muito embora eu a proferisse, eu mesmo sou um avesso desta constatação, haja vista que meu primeiro contato com a formação teatral se deu por meio da universidade. A despeito deste contrassenso, meu objetivo com esta provocação era fazer os discentes refletirem sobre as implicações da escolha em buscar uma vivência artística através do ensino superior, haja vista que tal trajeto é apenas mais um dos caminhos para formação do artista, não o único, e que, apesar de diferente, o aprendizado prático da vivência de cena é tão legítimo quanto o fazer universitário.

Tal provocação inicial aponta um aspecto curioso na formação do artista nacional. A legislação brasileira ${ }^{1}$ que rege a profissão ator/atriz regulamenta que, para seu exercício, o ensino superior não é o único meio de acesso, podendo o mesmo ser legitimado através de cursos técnicos/profissionalizantes ou ainda prática artística comprovada e aprovação mediante teste no sindicato. Ocorre que, ainda que existam estas possibilidades, indivíduos que desejam prioritariamente seguir carreira artística continuam se matriculando nos cursos de licenciatura e bacharelado em artes cênicas e teatro, fato que denota um interesse por este campo específico.

A meu ver, a escolha do caminho a ser traçado para formação deste artista possui consonância com o que o indivíduo deseja e, ao escolher dentre uma destas rotas, é possível inferir que tal decisão carrega as consequências inerentes ao campo de aprendizado elencado. Diante disto, me pergunto: o que implica buscar uma vivência e aprendizado artístico dentro da universidade? A partir deste questionamento, interessa então neste artigo compreender como a

\footnotetext{
${ }^{1}$ De acordo com o Art. $7^{\circ}$ da Lei 6.533/78: "Para registro do Artista ou do Técnico em Espetáculos de Diversões, é necessário a apresentação de: I - diploma de curso superior de Diretor de Teatro, Coreógrafo, Professor de Arte Dramática, ou outros cursos semelhantes, reconhecidos na forma da Lei; ou II - diploma ou certificado correspondentes às habilitações profissionais de $2^{\circ}$ Grau de Ator, Contraregra, Cenotécnico, Sonoplasta, ou outras semelhantes, reconhecidas na forma da Lei; ou III - atestado de capacitação profissional fornecido pelo Sindicato representativo das categorias profissionais e, subsidiariamente, pela Federação respectiva" (BRASIL, 1978).
} 
prática cênica invade o ensino superior brasileiro e a possível herança deste trajeto. Para tanto, traço um breve panorama do ensino de teatro no Brasil, tendo consciência que, ao realizar tal ato, em um texto curto, serão feitas escolhas que indubitavelmente não conseguirão comportar toda a complexidade e abrangência deste percurso e de todos os seus protagonistas.

\section{Teatro se ensina?}

Cabe lembrar que por um longo período a prática artística - mais especificamente o trabalho do ator/atriz - não pertenceu ao campo do ensino formal, quer seja superior, médio ou profissionalizante. De acordo com Enio Carvalho (1989), no Brasil, as primeiras tentativas para criação de campos formais na formação do artista não obtiveram êxito inicial. Para ele, as preocupações com esta formação mais estruturada para a prática cênica datam de 1846, através de um requerimento enviado à Câmara por um "[...] empresário teatral, cujo nome não se guardou" (p. 171) solicitando a criação de uma escola dramática. Como tal demanda não foi atendida, mais tarde, em 1861, o ator João Caetano realiza outra tentativa, enviando um pedido oficial ao Marquês de Olinda, mas também não obteve êxito.

Tal intento só começa a se edificar quase cinquenta anos depois com o Conservatório Dramático e Musical de São Paulo, fundado por Gomes Cardim em 1906. Entretanto, devido à inconstância ${ }^{2}$ das turmas que se formavam no curso de arte dramática lá oferecido, o ideal de uma formação oficial e continuada para o artista só foi se concretizar com a Escola Dramática Municipal do Rio de Janeiro $^{3}$, fundada em 1908 por Coelho Neto, e regulamentada três anos depois. Como aponta o pesquisador:

\footnotetext{
${ }^{2}$ De acordo com Paulo Luís de Freitas: "[...] é provável que o curso tenha existido de forma irregular, uma vez que, os registros de todos os alunos diplomados naquela instituição, durante o período de 1910 a 1931, revelam que apenas nos anos de 1910, 1911, 1912, 1916, 1921, 1924, 1927, 1929 e 1931 há formados no curso dedicado à arte de representar" (FREITAS, 1998, p. 23).

${ }^{3}$ Pouco após sua fundação foi rebatizada como Escola Dramática Martins Pena (EDMP) e atualmente se chama Escola Técnica Estadual de Teatro Martins Pena.
} 
Em 1911, o Rio de Janeiro instalou a Escola Dramática Municipal, que teria sido a primeira escola de teatro do Brasil e a realização do acalentado sonho de Coelho Neto, formando sua primeira turma de atores em 1913, e Procópio Ferreira, em 1915. (CARVALHO, 1989, p. 124)

Entretanto, a missão da escola de formar um novo ator para o teatro nacional, preparado para os desafios que o exercício do ofício the apresentaria, parece ter enfrentado uma série de entraves. Na época, o aprendizado artístico brasileiro estava intimamente vinculado ao fazer cênico, no qual o "aprendiz" exercitava na prática o que porventura observou do "mestre" que lhe ensinava o ofício. A cada ensaio e apresentação, somava à própria experiência uma nova vivência com a cena e, assim, ia construindo seu repertório e edificando o próprio saber. Este modo de aprendizado não se restringia ao Rio de Janeiro e era praticado em âmbito nacional. Mariângela Alves de Lima traça um breve recorte desta realidade que ainda resistia em São Paulo nos anos 40:

A formação do ator se faz ainda dentro do palco, a cada espetáculo, no ensaio e nas coxias. Os guardiões deste conhecimento são os atores mais velhos, transmitindo seus recursos pelo método da repetição e do acréscimo da sua própria experiência. A escola é o próprio palco e, nesse sentido, as companhias são pequenas corporações de ofício que ensinam, quotidianamente, de acordo com a necessidade específica do texto que vai entrar em cena. Esta forma de aprendizagem através do convívio, sedimentada por uma afinidade econômica (na medida em que o ator iniciante pode aliar o trabalho remunerado à aprendizagem), tem seu poder de atração inegável para quem deseja iniciar-se no ofício. (LIMA, 1989, p. 80)

Este "aprender em cima das tábuas"4 carregava pouca consonância com a concepção de uma escola de teatro e um aprendizado formal, visto que, o tipo de conteúdo oferecido pela instituição de Coelho Neto era fortemente influenciado pelo classicismo europeu e privilegiava um aprendizado teórico, uma prática teatral dominada pelo texto, na qual o ator era aquele que "dizia bem" as palavras.

\footnotetext{
${ }^{4}$ O termo faz referência a relação que Elza de Andrade (2005, p. 16) faz entre as duas tradições atoriais (ator burguês/dramático e ator cômico/popular) delimitadas por De Marinis (1997) e a formação do artista brasileiro. Para mais informações ver Andrade (2005), De Marinis (1997) ou ainda Souza (2013).
} 
Tal situação estava num contrassenso com a prática nacional que priorizava o teatro de revista e a comédia de costumes, estilos que enfatizam um personalismo ${ }^{5}$ do artista bem como uma "dramaturgia atoral", na qual o "grande ator" improvisa e enxerta falas ao longo do texto, os famosos "cacos".

A própria escolha dos docentes da instituição dificultava o diálogo com 0 que era realizado nos palcos, haja vista que em sua maioria eles não eram profissionais de teatro, mas ligados à Academia Brasileira de Letras. Diante deste panorama inicial, diversos artistas desacreditavam em um potencial aprendizado nas "escolas de teatro". A respeito deste ponto, Paulo Marcos Falco de Brito destaca em sua dissertação as falas de Dercy Gonçalves e Procópio Ferreira:

Procópio Ferreira, baluarte do teatro antigo, frequentou a Escola Dramática em seus primeiros anos. Em depoimento prestado ao SNT, em 1974, vai reforçar a ideia de que a escola não servia para nada, não ensinava nada: 'Essa coisa de Escola Dramática não dá resultado. Você sabe, sai de lá discutindo teatro e não sabendo fazer teatro' (FERREIRA, 1976, p. 98). Dercy Gonçalves, atriz também 'das antigas', expressa opinião semelhante em entrevista concedida a Eduardo Tolentino de Araújo: 'Escola de teatro eu acho uma babaquice. Escola de teatro... Eu acho uma babaquice. Porque ninguém aprende a ser. Quem é, é!'. (BRITO, 2011, p. 66)

Porém, a despeito deste descrédito inicial encontrado nas falas supracitadas, no fim dos anos 30 e ao longo da década de 40, a prática artística passou por revoluções cênicas que exigiram posturas diferenciadas dos artistas brasileiros. Neste momento, a ideia de grupo passa a se fortificar em detrimento a figura do "grande ator", o trabalho do diretor também passa a ganhar destaque e o teatro brasileiro moderno é invadido pelas ideias de Copeau, Stanislavski, Craig, Antoine, Meyerhold, fatores que, paulatinamente, deslocam a ênfase do princípio

\footnotetext{
${ }^{5}$ Como lembra Décio de Almeida Prado: "A vaidade do intérprete, em suma, coincidia com o seu interesse comercial. Identificar o artista, física e psicologicamente, conhecer-lhe os sestros, as manhas, era um prazer que não convinha negar às plateias" (PRADO, 1988, p. 21).

${ }^{6}$ Tais falas foram extraídas respectivamente da série "Depoimentos I. Rio de Janeiro: MEC/Funarte/SNT, 1976, p. 94-97", e de uma entrevista realizada com a atriz para a série "Grandes Damas" (2001), exibida pelo canal GNT.
} 
personalista e dividem espaço com a visão de um ator que estuda e se aperfeiçoa para o exercício do ofício.

Neste rastro, um movimento puxado principalmente por grupos de teatro amador passa a tentar desconstruir a proposição do que chamavam de "um teatro comercial, ligeiro e digestivo", defendendo que a atividade cênica também deveria ser compreendida como uma ação cultural e não puro divertimento. Seus membros, em sua maioria, pertenciam a classes sociais mais abastadas economicamente e se inspiravam em experiências e discursos teatrais praticados principalmente por encenadores europeus ${ }^{7}$. Tais grupos, como o Teatro do Estudante do Brasil (TEB), o Grupo de Teatro Experimental e, principalmente, a parceria estabelecida entre Ziembinski e Os Comediantes, na montagem de "O vestido de noiva", em 1943, surgiram então com proposições cênicas que ampliaram os modos de encaminhamento da prática do artista.

Desse modo, esta acepção do fazer cênico, somada ao clamor desta classe de artistas, suscitou o fortalecimento de núcleos de formação que visassem preparar os indivíduos para esta nova realidade da cena, dando surgimento ao longo dos anos a diversas outras escolas, tais como: o Curso Prático de Teatro (CPT), a Escola de Arte Dramática (EAD) de São Paulo, a Fundação Brasileira de Teatro (FBT), a Escola de Teatro da Universidade da Bahia (ETUB) em Salvador, entre outras, das quais os nomes mais recorrentes entre os pesquisadores investigados podem ser vistos na tabela abaixo.

ESCOLAS

PRINCIPAL

CIDADE

ANO DE

RESPONSÁVEL

Curso Prático de Teatro

Abadie Faria Rosa, por

Rio de Janeiro

CRIAÇÃO

(CPT) meio do Serviço Nacional de Teatro (SNT)

Escola Dramática do

Renato Viana

Porto Alegre

1942

Rio Grande do Sul ${ }^{*}$

Escola de

Arte Alfredo Mesquita

São Paulo

1948

Dramática (EAD)

Escola de Teatro do Adacto Filho

Salvador

1950

Clube Fantoches da

\footnotetext{
${ }^{7}$ Para mais informações sobre estas influências, ver Silva (1988, p. 28-39).
} 


\begin{tabular}{|c|c|c|c|}
\hline \\
\hline \multicolumn{4}{|c|}{ Maria Clara Machado } \\
\hline Teatro Duse ${ }^{*}$ & Paschoal Carlos Magno & Rio de Janeiro & 1952 \\
\hline $\begin{array}{l}\text { Fundação Brasileira de } \\
\text { Teatro (FBT) }\end{array}$ & Dulcina de Moraes & Rio de Janeiro & 1955 \\
\hline $\begin{array}{l}\text { Escola de Teatro da } \\
\text { Universidade Federal da } \\
\text { Bahia (ETUB) }\end{array}$ & Martim Gonçalves & Salvador & 1956 \\
\hline $\begin{array}{l}\text { Teatro Universitário, da } \\
\text { Universidade Federal de } \\
\text { Minas Gerais (UFMG) }\end{array}$ & Vicenzo Spinelli & Belo Horizonte & $1956^{8}$ \\
\hline $\begin{array}{lcr}\text { Curso } & \text { de } & \text { Arte } \\
\text { Dramática } & \text { da } & \text { URGS }^{9} \\
\text { (CAD) } & & \end{array}$ & Ruggero Jacobi & Porto Alegre & 1957 \\
\hline $\begin{array}{l}\text { Curso de Formação de } \\
\text { Atores da Universidade } \\
\text { de Pernambuco (CFA) }\end{array}$ & Graça Melo & Recife & 1958 \\
\hline $\begin{array}{lr}\text { Curso de } & \text { Arte } \\
\text { Dramática } & \text { da } \\
\text { Universidade } & \text { Federal do } \\
\text { Ceará (CAD) } & \end{array}$ & $\begin{array}{l}\text { José Maria Bezerra de } \\
\text { Paiva (B. de Paiva) }\end{array}$ & Fortaleza & 1960 \\
\hline $\begin{array}{l}\text { Escola de } \text { Teatro e } \\
\text { Dança da Universidade } \\
\text { Federal do Pará } \\
\text { (ETDUFPA) }\end{array}$ & $\begin{array}{l}\text { Maria Sylva Nunes e } \\
\text { Benedito Nunes }\end{array}$ & Belém & 1960 \\
\hline $\begin{array}{l}\text { Tabela } 1 \text { - Principais cur } \\
\text { fontes: Carvalho (1989), } \\
\text { (2017), UFPA (2017). } \\
\text { *Tais escolas funcionara } \\
\text { porém, resolvi citá-las de } \\
\text { bem como o fortalecimen }\end{array}$ & $\begin{array}{l}\text { s de teatro fundados e } \\
\text { eitas (1998), Santana } \\
\text { apenas por curtos } \\
\text { do a importância de su }\end{array}$ & $\begin{array}{l}0 \text { - } 1960 \\
\text { Leão (2009), } \\
\text { de tempo ( } \\
\text { ativas para as }\end{array}$ & $\begin{array}{l}\text { 011), UFMG } \\
\text { e } 5 \text { anos), } \\
\text { as vindouras, }\end{array}$ \\
\hline
\end{tabular}

\section{Teatro se ensina!}

Apesar da maior parte das escolas supracitadas terem iniciado seus modelos de formação como cursos livres, muitas se transformaram ao longo do tempo em cursos de nível técnico profissionalizante e, ainda, plantaram as sementes para o lançamento do ensino de teatro ao nível superior. Embora existissem críticas às diversas estruturas pedagógicas propostas pelas escolas

\footnotetext{
${ }^{8}$ Ainda que o Teatro Universitário tenha sido inaugurado em 1952, somente em 1956 passou a oferecer um curso regular para atores.

${ }_{9}^{9}$ A Universidade do Rio Grande do Sul (URGS), apesar de ter sido federalizada nos anos 50, só teve sua nomenclatura alterada para Universidade Federal do Rio Grande do Sul (UFRGS) em 1965. Para mais informações sobre este processo verificar Cunha (2009, p. 48).
} 
que, em sua maioria, as acusavam de enfatizar um aprendizado excessivamente teórico e apresentarem condições adversas para execução de um bom trabalho prático (poucos professores capacitados, muitos alunos...) ${ }^{10}$, a persistência destas instituições e seus fundadores contribuiu para a concepção de um artista que estuda e se aperfeiçoa, ou seja, de um indivíduo que não está condicionado estritamente a aspectos efêmeros como a genialidade e o talento.

Nesta perspectiva, a formação dos artistas brasileiros passa a ser cada vez mais valorizada, fazendo com que seu ofício seja compreendido como algo além de um pano de fundo, no qual o indivíduo projeta sua personalidade e aptidão natural, mas possua também uma série de recursos técnicos e uma compreensão intelectual do que antecede e circunda a concepção do ato teatral, bem como de suas proposições cênicas. Concomitantemente $a$ isto, o que antes era uma profissão estigmatizada, associada a "marginais e vigaristas"11, ganha reconhecimento social e adeptos da burguesia nacional.

Esta concepção de um artista que se aperfeiçoa somada à invasão burguesa favoreceu a ideia de lançar o ensino de teatro para o nível superior e, em setembro de 1945, Getúlio Vargas assinou o Decreto-Lei 7.958/45 que transformaria o Curso Prático de Teatro $(\mathrm{CPT})^{12}$ em Conservatório Nacional de Teatro (CNT), vinculando-o à Universidade do Brasil, e elevando o grau de seus concludentes para o nível superior. Contudo, tal intento não se concretizou, pois o decreto não entrou em vigor devido à queda de Getúlio no mês subsequente a assinatura.

Porém, mesmo que o decreto não tenha se efetivado, o desejo latente de elevar o ensino de teatro a nível universitário se traduziu em algumas ações, dentre elas, a realização do Primeiro Congresso Brasileiro de Teatro (1951). No evento em questão, se reuniram artistas e representantes de diversas instituições

\footnotetext{
${ }^{10}$ A respeito destas críticas, sugiro ao leitor verificar o estudo de Freitas (1998, p. 36-39), o comentário de Oscar (1957, p. 35-36), ou ainda Lima (1989, p. 82-83).

${ }_{11}$ A respeito disto, ver o artigo de Maciel $(1968$, p. 52).

12 Ao longo dos anos, o CPT passou por diversas reformulações. Em 1953, foi renomeado como Conservatório Nacional de Teatro (CNT); em 1969, foi desvinculado do Serviço Nacional de Teatro para compor a então Federação das Escolas Federais do Estado da Guanabara (FEFIEG) e passou a se chamar Escola de Teatro da FEFIEG; em 1975, quando Guanabara passou a fazer parte do Rio de Janeiro, compôs a Federação das Escolas Federais do Estado do Rio de Janeiro (FEFIERJ); e, em 1979, com a consolidação da UNIRIO se tornou a Escola de Teatro do Centro de Letras e Artes da UNIRIO.
} 
que submeteram 47 propostas $^{13}$, das quais, destaco a intitulada "Conservatório Nacional de Teatro", de Tomás Santa Rosa e José Carlos Lisboa. Tal trabalho solicitava o cumprimento do decreto que fora esquecido em 1945, bem como a formação de professores de teatro para inserção do ensino nas escolas primárias e secundárias. Tais educadores atuariam como orientadores de atividades dramáticas, ou seja, pode-se observar aqui que a ideia do ensino de teatro se fortificava e trazia consigo um dos primeiros clamores de algo que viria a se assemelhar às licenciaturas.

Não obstante, este desejo inalcançado de lançar o ensino do teatro ao nível universitário se configurou nas sucessivas reformas curriculares sofridas pelo CPT. Por estar vinculado ao Serviço Nacional de Teatro (SNT), órgão público federal, tais reformas ocorreram através de portarias ministeriais nos anos 1949, 1950 e 1952, das quais cabe destacar esta última, a Portaria $n^{\circ}$ 47/1952. Nela, o CPT manteve o status de curso livre, mas, ao visar uma formação mais acadêmica, inflou o curso de tal maneira que the atribuiu uma proposta de ensino que almejava abordar um excesso de conteúdo, onde o aspirante a ator deveria ter, além do conjunto de aulas práticas (técnica e arte de representar, dicção, esgrima, ginástica rítmica...), aulas de história nas mais diferentes linguagens (dança, música, teatro, artes plásticas e da cultura), bem como aulas de francês, italiano, inglês, espanhol e suas respectivas literaturas.

Este óbvio "inchaço" disciplinar visava prover uma formação cultural ampliada para os praticantes de teatro, aproximando-os cada vez mais da academia, porém, tal currículo nunca foi posto em prática por completo haja vista a própria estrutura que demandaria e a resistência de uma parcela da classe artística. Afinal, como alerta Silvia Fernandes, "[...] esse aprendizado exaustivo da cultura teatral, ainda que fundamental, nem sempre manteve relações estreitas com a prática do teatro" (FERNANDES, 2010, p. 195).

No ano seguinte, o CPT finalmente se torna Conservatório Nacional de Teatro (CNT), mas ainda não atinge o grau universitário. Tal intento só ocorreu em 1964, quando o Serviço Nacional de Teatro estava sob direção de Bárbara

${ }^{13}$ Para mais informações sobre o congresso, ver Camargo (2012a) e (2012b). 
Heliodora e, ao reestruturar os currículos do Conservatório, passou a oferecer a formação em nível superior nos cursos de Cenografia e Direção, bem como a formação de nível médio no curso de Interpretação. Tal movimento ocorreu em consonância a uma proposta de regulamentação do ensino de teatro e seus profissionais correspondentes que foi homologada no ano seguinte: a Lei 4.641/65. Nela, se instituiu:

Art. 1ํ Para todos os efeitos legais, são categorias definidas: 1. Diretor de Teatro. 2. Cenógrafo. 3. Professor de Arte Dramática. 4. Ator. 5. Contra-regra. 6. Cenotécnico. 7. Sonoplasta.

Art. 2 0 Diretor de Teatro, o Cenógrafo e o Professor de Arte Dramática serão formados em cursos de nível superior, com duração e currículo mínimo fixados pelo Conselho Federal de Educação.

Art. 3ㅇ 0 Ator, o Contra-regra, o Cenotécnico e o Sonoplasta serão formados em cursos únicos de nível médio, organizados de acordo com o parágrafo único do art. 47 da Lei no 4.024, de 20 de dezembro de 1961. [Grifos meus] (BRASIL, 1965)

Seguindo o rastro deste movimento, outras escolas livres passaram a dialogar com as universidades e darem forma a mais cursos superiores em meados dos anos 60, e, como lembra Arão Paranaguá de Santana, em alguns casos, estas escolas "[...] emprestaram não somente as bases conceituais e metodológicas, mas também professores e programas de ensino" (SANTANA, 2000, p. 45). Por exemplo, a Escola de Arte Dramática (EAD) de São Paulo foi absorvida pela USP e, a partir do currículo dos cursos de Dramaturgia e Crítica Teatral, oferecidos na EAD, moldou em 1966 o curso superior de arte dramática com habilitação em dramaturgia e crítica que, posteriormente, também incorporou as habilitações em direção, cenografia e professorado. A Escola de Teatro da UFBA passou a oferecer a formação superior de Direção Teatral. O Curso de Arte Dramática da URGS deu forma ao curso superior em direção e professorado. Desse modo, no início da década de 70, somando tais instituições ao CNT, havia quatro cursos superiores em teatro no Brasil.

A partir deste ponto, creio ser interessante observar que um dos principais eixos temáticos trabalhados atualmente nas pesquisas de graduação e pós- 
graduação, o trabalho do ator e atriz, não fora considerado inicialmente para compor o conjunto de cursos do ensino superior delimitados pela lei. Na tentativa de apontar os motivos destes encaminhamentos, cabe rever alguns dos depoimentos que animavam a discussão da época. A visão do ofício em nível universitário não era consenso entre a classe artística, como pode ser observado nos pequenos artigos publicados por Henrique Oscar e Maria Clara Machado, em 1963:

Há um velho mito de que o ensino dramático deve ser elevado ao nível universitário para poder ter o desenvolvimento e a profundidade necessários, etc. e pode-se acrescentar uma série de outras razões impressionantes, mas demagógicas. O ensino universitário brasileiro é extremamente rígido, tem uma estrutura de todo inadequada para o aprendizado de uma arte como o teatro, que requer uma flexibilidade enorme. (OSCAR, 1963, p. 6)

Como bem disse Henrique Oscar em seu artigo, o ensino dramático deve ser de nível técnico, exigindo portanto, que o aluno traga de fora os conhecimentos adquiridos no curso ginasial [...] Partindo da realidade brasileira, daquilo com que podemos contar em matéria de professores e dado o nível dos alunos, igualmente, é preciso não sonhar com a escola universitária de artes dramáticas, pois ainda é cedo para isso. (MACHADO, 1963, p. 7)

Ora, se as principais críticas realizadas sobre as escolas de teatro em funcionamento enfocavam seu aspecto excessivamente teórico e a existência de poucas aulas práticas, a ideia de lançar a formação do artista para o ensino superior, campo reconhecido por seu caráter prioritariamente acadêmico, confrontava diretamente esta situação.

Nesta perspectiva, entendendo o trajeto de formação do artista brasileiro e sua dificuldade inicial de relação com as escolas, há de se compreender o receio em lançar o aprendizado do ofício ao nível superior. Muito embora instituições como a Escola de Arte Dramática de São Paulo já tivessem proposto uma outra visão para o trabalho do ator/atriz, na qual se enfatiza o seu aspecto cultural e 
intelectual $^{14}$, e, ainda, cursos de nível médio de interpretação ainda estivessem ligados a universidades (Escola de Teatro - UFBA, Teatro Universitário - UFMG, Curso de Arte Dramática - URGS, Curso de Arte Dramática - UFC, Centro de Formação de Atores - UFPE, Escola de Teatro e Dança - UFPA), o artista da cena ainda era considerado um artesão e, caso a regulamentação do ofício se tornasse exclusivamente universitária, corria-se o risco de intelectualizar excessivamente $o$ trabalho e fechar o acesso à profissão de maneira repentina.

Contudo, alguns anos depois, em 1971, a Federação das Escolas Federais do Estado da Guanabara (FEFIEG) e a Fundação Brasileira de Teatro (FBT) sediaram o "I Simpósio Nacional de Ensino de Teatro", no qual defenderam uma posição diferenciada na plenária final. Ora, se o ensino superior de teatro já era uma realidade e suas profissões decorrentes haviam sido regulamentadas, o ator também deveria ser considerado um artista criador. Neste sentido, realizaram uma proposição curricular para os cursos universitários em vigor e defenderam a criação do curso de atores em nível superior, bem como a inclusão do ensino de teatro nas instituições de $1^{\circ}$ e $2^{\circ}$ grau.

Ocorre que o governo brasileiro toma uma atitude que contempla uma parcela desta solicitação, mas a executa de uma maneira distorcida e amorfa através da Lei $n^{0} 5.692 / 71$. Dentre as diversas diretrizes por ela impostas, o ensino de arte passou a ser obrigatório nos currículos de instituições de $1^{\circ}$ e $2^{\circ}$ grau. Porém, apesar de aparentemente positiva, tal orientação criou uma situação adversa, na qual os professores, independentemente de suas especificidades, deveriam dar conta de todos os aspectos das mais diferentes linguagens na forma de uma disciplina chamada "educação artística". Evidentemente, este caráter

\footnotetext{
${ }^{14}$ Sobre este tópico, cabe citar o destaque teórico que a proposta do fundador da EAD, Alfredo Mesquita, dava ao currículo de sua escola. Como se pode ver nos escritos de Armando Sérgio da Silva: "No que diz respeito à formação cultural do aluno, considerada prioritária por Alfredo Mesquita, havia, em primeiro lugar, ênfase muito grande no ensino da história do teatro universal e, especificamente, no teatro grecoromano, clássico francês e elisabetano. Para se ter uma ideia da importância dada a esse conhecimento histórico, vejam-se os seguintes dados: de um total de 1200 aulas, incluindo-se aí aquelas dedicadas às montagens de espetáculo, a matéria consumia, em geral, cerca de 350 horas, ou seja $30 \%$ do total. Como se isso não bastasse, era eliminatória nos dois primeiros anos. Isso quer dizer que, por mais talentoso que fosse o aluno, não poderia continuar cursando a escola, se fosse reprovado nessa matéria". (SILVA, 1988, p. 61)
} 
polivalente contribuiu para a construção de uma visão depreciativa sobre o ensino da arte. Como fala Ricardo Japiassú:

A obrigatoriedade da educação artística e a forma autoritária de sua implantação comprometeram a qualidade do ensino de artes oferecido nas escolas, arranharam a imagem dos profissionais habilitados para o trabalho com a matéria na educação escolar e impediram o desenvolvimento de um tratamento pedagógico consequente de seus conteúdos. (JAPIASSÚ, 2009, p. 64)

Tal normativa gerou um crescimento desenfreado de cursos superiores para atender a incrível demanda que o ensino obrigatório gerou por estes "professores polivalentes" que não existiam. Em oposição ao processo anterior, a maioria destes cursos superiores de "Licenciatura em Educação Artística" não seguiu um processo pedagógico pautado por profissionais da área e nem foram herdeiros de escolas de arte em atividade, mas surgiram para sanar as necessidades impostas pelo modelo de ensino que o regime militar exigia. Como pode ser visto nas palavras de Santana:

É importante registrar que, diferentemente de quando foram criados os primeiros cursos superiores de Teatro, o poder público não deu atenção à voz daqueles que lidavam com essa questão quando reelaborou a formação do professor das disciplinas artísticas e homologou o currículo mínimo da licenciatura em Educação Artística. Naquele momento, foi desconsiderada a tradição escolar e a experiência acadêmica, calando as vozes que podiam manifestar-se com conhecimento abalizado. (SANTANA, 2000, p. 83, 84)

Muito embora tal movimento tenha difundido cursos superiores voltados para o ensino de arte no Brasil, creio que o ato carregou consigo algumas problemáticas. Dentre elas, ressalto a figura do professor polivalente, que planificava as discussões que as diferentes linguagens artísticas poderiam gerar, bem como a falta de estrutura das universidades para atender esta demanda repentina, gerando uma série de cursos improvisados e sem conteúdo aprofundado. 
No meio deste turbilhão, em 1974, a resolução $n^{\circ} 32 / 74$, do Conselho Federal de Educação, é aprovada e regulamenta o bacharelado em artes cênicas com as habilitações em direção, cenografia, teoria teatral e, finalmente, interpretação. Desse modo, enfim, o ator ingressa no ensino superior e começam a surgir bacharelados com habilitações específicas para formação destes profissionais. Ocorre que, na definição federal do currículo mínimo destas habilitações, as orientações feitas em 1971 pelo simpósio da FEFIEG e FBT não foram levadas em consideração, construindo inicialmente uma tarefa árdua para a formação do artista na universidade ao ignorar os argumentos daqueles que já trabalhavam, refletiam e contribuíam com a área.

Com base nestas observações, é possível notar os diversos percalços que a prática teatral passou para que sua ideia de ensino fosse legitimada e lançada à formação universitária. Trilhar este caminho exigiu lidar com os atritos entre uma prática teatral apreendida no ofício, uma lógica curricular que poderia ser excessivamente "academicista" e, ainda, as influências de uma ditadura militar ditando normas e maneiras de conduta. Muitas mudanças ainda irão acontecer nesta trajetória do ensino superior de teatro brasileiro até à chegada aos dias de hoje, mas opto por não continuar esta retrospectiva histórica de maneira direta para que, assim, possa refletir um pouco sobre as influências destas origens na formação que se promove hoje nas universidades.

\section{Implicações desta trajetória: uma herança cômico-popular-europeia- moderna-militar-educativa?}

Cabe destacar inicialmente um aspecto que considero curioso, a legislação anterior (Lei 4.641/65), que mantinha a formação do ator a nível secundário, é mantida e, com isso, a habilitação escolar deste profissional coexiste pelo Brasil em dois níveis distintos, o médio e o superior. Soma-se a isto a possibilidade apresentada inicialmente neste texto, a regulamentação mediante prática teatral comprovada e teste no sindicato. Nesta ótica, a legitimação profissional deste artista da cena é um depoimento de sua trajetória de formação no Brasil, na qual, 
no início, seu aprendizado se dava exclusivamente nas tábuas, depois poderia também recorrer às escolas e, finalmente, sua formação pode se dar ainda em âmbito superior.

Sobre este último campo é válido ressaltar que as quatro primeiras faculdades (UNIRIO, USP, UFBA e UFRGS) a promoverem cursos superiores de teatro foram herdeiras das escolas pioneiras na formação de atores e das discussões que lá ocorriam. Neste sentido, pode-se inferir que elas traçaram as bases para o que viria a ser o modelo dos cursos superiores de teatro que surgiriam depois no Brasil, mas, ocorre que, com as imposições da ditadura militar, muitos dos argumentos e discussões da classe artística não conseguiram adentrar inicialmente os portões das universidades devido à dureza do regime. $\mathrm{A}$ própria lógica de ensino que fora pautada pelas universidades supracitadas teve que se reestruturar em alguma medida com os desmandos do sistema vigente.

Ainda neste rastro, estando dentro das universidades, a formação teatral também sofreu com a reforma universitária praticada em 1968. A ideia do regime militar de formar profissionais para o mercado de trabalho e a imposição de um ensino tecnicista ecoou de maneira direta nos cursos. Ainda que no campo das artes tenha ocorrido com ênfase inicial nas licenciaturas, devido à "invencionice" da educação artística, em alguma medida este modelo invadiu também os bacharelados, haja vista a reestruturação pedagógica que esta medida impôs. Como aponta Dermeval Saviani, na reforma proposta pelos militares, o papel do ensino superior era "[...] formar a mão-de-obra especializada requerida pelas empresas e preparar os quadros dirigentes do país" (SAVIANI, 2008, p. 295). Muito embora o teatro não se enquadre perfeitamente nesta definição, a perspectiva proposta por este tipo de educação impôs um tipo de ensino instrumental, vinculado diretamente às "necessidades do país" que, em alguma medida, pode ter limitado a criação artística livre, submetendo-a não apenas à censura natural do regime, mas também ao encaminhamento pedagógico traçado. Tal aspecto é reiterado nas palavras de Brito: 
A tendência tecnicista da pedagogia oficial, implantada por meio da Reforma Universitária de 1968, vai se configurar como um grande obstáculo às necessidades específicas dos cursos de formação artística, como a teatral. É possível deduzir daí as dificuldades enfrentadas pelos quatro cursos pioneiros que, criados sob outra orientação, se viram obrigados a adaptar-se aos novos tempos. (BRITO, 2011, p. 132)

Soma-se a isto o fato da censura dominante passar a limitar textos, ações cênicas e pesquisas desenvolvidas no seio da graduação, bem como nas pósgraduações que surgiriam, como no caso do Programa de Pós-Graduação em Artes Cênicas, da Eca-USP, nascido ainda em 1981. Na tentativa de fugir da repressão do regime, as pesquisas desenvolvidas se focaram inicialmente em temas mais neutros e que não dialogavam necessariamente com as questões políticas aventadas, ainda que constantemente reprimidas, nos palcos teatrais. De acordo com Edelcio Mostaço:

Como se deve recordar, vivíamos sob a Ditadura Militar, de modo que as investigações iniciais seguiram por temas e abordagens não polêmicos, tais como o trabalho do ator, do encenador, tendências históricas da dramaturgia em certos recortes de tempo, a pedagogia teatral, além de autores, encenadores, cenógrafos e outros profissionais. Dadas as restrições censórias da época, as pesquisas voltaram-se para temas internacionais ou aqueles que não enfrentassem posicionamentos ideologicamente espinhosos do passado recente. (MOSTAÇO, 2015, p. 25)

Eventualmente, com a abertura do regime, o aumento e divulgação das pesquisas na área, a autonomia universitária, a abertura e difusão de novas universidades através do Reuni ${ }^{15}$, esta realidade no ensino teatral foi (e vem) mudando, mas cabe aqui pensar sobre esta trajetória.

Ora, se nos anos 20, esta herança cômico-popular, dada nas tábuas do palco, restringia-se a um teatro ligeiro, ou ainda, "[...] farsas brejeiras e comédias de costumes sem visco maior que a comunicação fácil com plateias incultas"

\footnotetext{
${ }^{15}$ O Programa de Apoio a Planos de Reestruturação e Expansão das Universidades Federais (Reuni) foi instituído em 2007 e tinha como objetivo ampliar o acesso e permanência no ensino superior. Para tanto, promoveu uma série de medidas que promoveram a expansão física e acadêmica da rede federal de educação superior.
} 
(MOSTAÇO, 2015, p. 22), ocorreu uma proposta de transgressão que buscou mudar esta realidade cênica através da formação de um novo ator/atriz nas escolas, um artista que seria capaz de praticar o teatro moderno que se anunciara. Entretanto, muito embora tal proposição tenha surgido com objetivos nobres, esta transgressão foi fortemente contaminada por indícios e traços de discursos europeus, promovendo um teatro com ares burgueses que pouco dialogava com o público. Sabendo que estas escolas promoveram os primeiros currículos que moldaram os cursos superiores, é possível inferir então que foi este tipo de prática teatral que adentrou nas universidades, explicando talvez um certo receio inicial de inserção de práticas cômico populares no ambiente acadêmico.

No rastro desta herança, a ditadura militar impôs condições que alçaram o ensino de teatro ao âmbito superior, mas restringiram seus modos de fazer, quer seja através da censura direta ou pelo modelo pedagógico que estruturou a universidade e os cursos nascentes. Diante destas observações, facilmente é possível inferir que esta herança influenciou traços curriculares, práticas abordadas, estéticas de montagem e encenadores a serem estudados. Cabe então refletir que, de alguma maneira, tais consequências ainda podem estar impregnadas nos currículos vigentes e, principalmente, em nossos modelos de ensino. A própria lógica disciplinar dos cursos de graduação é uma parcela desta tradição, haja vista que sua rigidez por vezes não consegue acompanhar as mudanças e rupturas estéticas que as práticas cênicas atuais propõem.

Contudo, afirmar que houve influências que determinaram os caminhos escolhidos não significa dizer que os trajetos estão selados. Os investimentos que ocorreram nas universidades, através do fortalecimento do tripé ensino-pesquisaextensão e da ampliação de vagas, colocaram outras perspectivas, pessoas e profissionais em contato com este ambiente formativo. Se, em seu início, a universidade brasileira era um campo de formação elitista e prioritariamente burguês, a retomada da expansão do ensino superior nos anos 2000 favoreceu a entrada de indivíduos que dificilmente teriam acesso ao ambiente acadêmico e, com isto, diversificou em alguma medida o perfil dos sujeitos que compõem a universidade. 
Ora, a herança europeia das escolas, que antes dialogava com o público elitizado que habitava a universidade, passa a conviver com discentes e docentes que não a coadunam e, com isto, conclamam o surgimento de outras disciplinas e modos de fazer que dialoguem com a realidade destes indivíduos. No contexto do ensino superior em teatro, estes conflitos abrem campo para outras pesquisas e estéticas que aproximam manifestações populares, artistas e grupos teatrais nacionais em atividade, da prática universitária. Com isso, o ensino de teatro na universidade tende a se diversificar e estabelecer um contato cada vez mais íntimo com o cenário nacional, promovendo então outras formas de fazer que, por vezes, encontram dificuldades em se encaixar nos modelos acadêmicos já traçados. Certamente ainda existem desafios a serem vencidos para fortalecimento destes diálogos, haja vista a estrutura excessivamente disciplinar ou puramente tecnicista que por vezes ressurge nestes campos de formação e sufoca o processo de criação artística livre. Acredito então que escolher uma formação artística no ensino superior traz consigo uma herança, mas que pode ser mudada de acordo com as necessidades, vontades e empenho daqueles que dela participam.

Recebido em 27/06/2019

Aceito em 22/09/2019

\section{Referências}

ANDRADE, Elza de. Mecanismos de comicidade na construção do personagem: propostas metodológicas para o trabalho do ator. 2005. 208f. Tese (Doutorado em Teatro) - Centro de Letras e Artes, Universidade Federal do Rio de Janeiro, Rio de Janeiro, 2005.

BRASIL. Lei nº 4.641, de 27 de maio de 1965. Brasília, DF, maio 1965.

BRASIL. Lei n ${ }^{\circ} 6.533$, de 24 de maio de 1968. Brasília, DF, maio 1978.

BRITO, Paulo Marcos Falco de. A (in) desejada transgressão: uma história social do Ensino Superior de Teatro no Brasil. 2011. 214f. Dissertação (Mestrado 
em Educação) - Faculdade de Educação, Universidade de São Paulo, São Paulo, 2011.

CAMARGO, Angélica Ricci. As ideias em debate no Primeiro Congresso Brasileiro de Teatro (1951). ArtCultura, Uberlândia, n. 24, v. 14, p. 153-166, $2012 a$.

CAMARGO, Angélica Ricci. Nos palcos e na política: as organizações dos profissionais teatrais na primeira metade do século XX. Baleia na rede - estudos em arte e sociedade, São Paulo, n. 1, v. 9, p. 34-51, 2012b.

CARVALHO, Enio. História e formação do ator. São Paulo: Ática, 1989.

CUNHA, Janaína Dias. A reforma universitária de 1968 e o processo de reestruturação da UFRGS (1964 - 1972): uma análise da política educacional para o ensino superior durante a ditadura civil-militar brasileira. 2009. 213f. Dissertação (Mestrado em Educação), Universidade do Vale do Rio dos Sinos, São Leopoldo, 2009.

DE MARINIS, Marco. Compreender el teatro: lineamentos de uma nueva teatrologia. Buenos Aires: Galerna, 1997.

FERNANDES, Silvia. Teatralidades Contemporâneas. São Paulo: Perspectiva, 2010.

FREITAS, Paulo Luís de. Tornar-se ator: uma análise do ensino de teatro no Brasil. Campinas: Editora da UNICAMP, 1998.

JAPIASSÚ, Ricardo. Metodologia do ensino de teatro. São Paulo: Papirus, 2009.

LEÃO, Raimundo Matos de. A casa de Eros e Dionísio: um projeto de ensino e encenação. Cena. Porto Alegre, n. 7, p. 42-55, 2009.

LIMA, Mariângela Alves de. A formação do ator. Revista Dionysos. Rio de Janeiro, n. 29, p. 79-96, 1989.

MACHADO, Maria Clara. O ensino dramático. Cadernos de Teatro, Rio de Janeiro, n. 21, p. 7, 1963.

MACIEL, Luís Carlos. Quem é quem no Teatro Brasileiro: Estudo sóciopsicanalítico de três gerações. Revista Civilização Brasileira, Rio de Janeiro, a. 4, n. 2, p. 49-68, 1968.

MOSTAÇO, Edelcio. A teoria do teatro numa Roma tropical. Caixa de Pont[o] jornal brasileiro de teatro. Florianópolis, n. 1, p. 22-28, 2015. 
OSCAR, Henrique. O perigo na criação de novas escolas de teatro. Cadernos de Teatro, Rio de Janeiro, n. 9, p. 35-36, 1957.

OSCAR, Henrique. O ensino dramático também deve ser reestruturado. Cadernos de Teatro, Rio de Janeiro, n. 21, p. 6-7, 1963.

PRADO, Décio de Almeida. Teatro brasileiro moderno: 1930 - 1980. São Paulo: Perspectiva, 1988.

SANTANA, Arão Paranaguá de. Teatro e formação de professores. São Luís: EDUFMA, 2000.

SAVIANI, Dermeval. O legado educacional do regime militar. Cadernos CEDES, Campinas, v. 28, n. 76, p. 291-312, 2008.

SILVA, Armando Sérgio da. Uma oficina de atores: a Escola de Arte Dramática de Alfredo Mesquita. São Paulo: Editora da USP, 1988.

SOUZA, Henrique Bezerra de. 0 ator na cena cômica: o gesto como via de construção da comicidade. 2013. 135f. Dissertação (Mestrado em Artes Cênicas) - Escola de Teatro, Universidade Federal da Bahia, Salvador, 2013.

UFMG.

Histórico.

Disponível

em: http://www.coltec.ufmg.br/tu/\#!/pagina/8/historico. Acesso em: 10 de outubro de 2017.

UFPA. ICA Histórico. Disponível http://www.ica.ufpa.br/index.php?option=com_content\&view=article\&id=1. Acesso em: 10 de outubro de 2017. 